Warmelink, J.C., Wiegers, T.A., Cock, T.P. de, Klomp, T., Hutton, E.K. Collaboration of midwives in primary care midwifery practices with other maternity care providers. Midwifery: 2017, 55(12), 45-52

\begin{tabular}{|l|l|}
$\begin{array}{l}\text { Postprint } \\
\text { Version }\end{array}$ & 1.0 \\
\hline Journal website & $\underline{\text { http://www.midwiferyjournal.com/article/S0266-6138(16)30356-4/fulltext }}$ \\
\hline Pubmed link & $\underline{\text { https://www.ncbi.nlm.nih.gov/pubmed/28926751 }}$ \\
\hline DOI & $10.1016 /$ j.midw.2017.08.010 \\
\hline
\end{tabular}

This is a NIVEL certified Post Print, more info at http://www.nivel.eu

\title{
Collaboration of midwives in primary care midwifery practices with other maternity care providers
}

\author{
J. CATJAW ARMELINKPHD(DR. $)^{A B}$ THERESE A.WIEgERSPhD(DR. $)^{\mathrm{C}}$ T. PAULDE \\ COCKPHD(DR.) ${ }^{\mathrm{ABD}}$ TrudyKLOMPPHD(DR.) $)^{\mathrm{AB}}$ EILEEN K.HUTTONRM, PHD(PrOF. $)^{\mathrm{AE}}$ \\ ${ }^{a}$ Midwifery Science, AVAG, Amsterdam Public Health research institute, VU University \\ Medical Center, Amsterdam, The Netherlands \\ ${ }^{b}$ Midwifery Academy Amsterdam Groningen, The Netherlands \\ ${ }^{c}$ Netherlands institute for health services research (NIVEL), Utrecht, The Netherlands \\ ${ }^{d}$ The Bamford Centre for Mental Health and Wellbeing, University of Ulster, Coleraine, \\ United Kingdom \\ ${ }^{\mathrm{e}}$ Faculty of Health Sciences, McMaster University, Hamilton, Canada
}

\begin{abstract}
Background: Inter-professional collaboration is considered essential in effective maternity care. National projects are being undertaken to enhance interprofessional relationships and improve communication between all maternity care providers in order to improve the quality of maternity care in the Netherlands. However, little is known about primary care midwives' satisfaction with collaboration with other maternity care providers, such as general practitioners, maternity care assistance organisations (MCAO), maternity care assistants (MCA), obstetricians, clinical midwives and paediatricians. More insight is needed into the professional working relations of primary care midwives in the Netherlands before major changes are made

Objective: To assess how satisfied primary care midwives are with collaboration with other maternity care providers and to assess the relationship between their 'satisfaction with collaboration' and personal and work-related characteristics of the midwives, their attitudes towards their work and collaboration characteristics (accessibility). The aim of this study was to provide insight into the professional working relations of primary care midwives in the Netherlands.

Methods: Our descriptive cross-sectional study is part of the DELIVER study. Ninety nine midwives completed a written questionnaire in May 2010. A Friedman ANOVA test assessed differences in satisfaction with collaboration with six groups of maternity care providers. Bivariate analyses were carried out to assess the relationship between satisfaction with collaboration and personal
\end{abstract}


and work-related characteristics of the midwives, their attitudes towards their work and collaboration characteristics.

Results: Satisfaction experienced by primary care midwives when collaborating with the different maternity care providers varies within and between primary and secondary/tertiary care. Interactions with non-physicians (clinical midwives and $\mathrm{MCA}(\mathrm{O})$ ) are ranked consistently higher on satisfaction compared with interactions with physicians (GPs, obstetricians and paediatricians). Midwives with more work experience were more satisfied with their collaboration with GPs. Midwives from the southern region of the Netherlands were more satisfied with collaboration with GPs and obstetricians. Compared to the urban areas, in the rural or mixed areas the midwives were more satisfied regarding their collaboration with $\mathrm{MCA}(\mathrm{O}) \mathrm{s}$ and clinical midwives. Midwives from non-Dutch origin were less satisfied with the collaboration with paediatricians. No relations were found between the overall mean satisfaction of collaboration and workrelated and personal characteristics and attitude towards work.

Conclusions

Inter-professionals relations in maternity care in the Netherlands can be enhanced, especially the primary care midwives' interactions with physicians and with maternity care providers in the northern and central part of the Netherlands, and in urban areas. Future exploratory or deductive research may provide additional insight in the collaborative practice in everyday work setting.

AbBreviations

AVAG

Midwifery Academy Amsterdam Groningen

ANOVA

ANalysis Of VAriance;

AVAG

Midwifery Academy Amsterdam Groningen

CPZ

College Perinatale Zorg

DELIVER

Data EersteLIjns VERloskunde

GP

General Practitioner

WSC

Well Satisfied with Collaboration

ITL

Intention To Leave

LSC

Less Satisfied with Collaboration

MCA

Maternity Care Assistant

MCAO

Maternity Care Assistance Organisation

KNOV 
Warmelink, J.C., Wiegers, T.A., Cock, T.P. de, Klomp, T., Hutton, E.K. Collaboration of midwives in primary care midwifery practices with other maternity care providers. Midwifery: 2017, 55(12), 45-52

Royal Dutch Association of Midwives

NIVEL

Netherlands institute for health services research;

SD

Standard Deviation

UK

the United Kingdom

VIL

Obstetric Indication List

VUmc

Free University medical centre

WHO

World Health Organisation

\section{BACKGROUND}

Maternity care in the Netherlands is divided into primary and secondary/tertiary care, similar to the overall organisation of the Dutch healthcare system (Rowland et al., 2012). In Box 1 a short overview is given of the collaboration in maternity care in the Netherlands.

\section{[BOX 1]}

Close inter-professional collaboration is considered essential in effective maternity care (WHO, 1978; Frank\&Danoff, 2007; Downe et al., 2010; de Geus and Cadée, 2015; de Jonge et al., 2015; ten Hoope-Bender, 2016). Unique as it may be, the Dutch maternity system is characterised by an edgy paradox. On the one hand, other countries, such as Canada, the United Kingdom and New Zealand took the Netherlands as an example for changing their maternity care systems (de Vries et al., 2009). On the other hand, within the Netherlands, the quality of care of the 'Dutch' way of maternity care organisation has been increasingly brought into question (Warmelink, 2017). A variety of Dutch studies showed that collaboration and communication between the maternity care professionals within and between these echelons at times falls short of the high standards women should expect. For example, Schölmerich et al. (2014) found fragmented organizational structures, different perspectives on antenatal health and inadequate inter-professional communication in the collaboration between primary care midwives, obstetricians and clinical midwives. van der Lee et al. (2016) found that primary care midwives in their collaboration with obstetricians experienced a power imbalance, a lack of trust and mutual acquaintanceship. Warmelink et al. (2015) found that primary care midwives felt that co-operation and communication with other health care disciplines in general could be improved.

Problems with communication and collaboration among maternity care providers can threaten the quality and safety of care given to mothers and babies (Joint Commission on Accreditation of Healthcare Organizations, 2004; Simpson and Knox, 2003). National projects in the Netherlands are being undertaken to enhance inter-professional relationships and improve communication between all maternity care providers and the client $(\mathrm{CPZ}, 2014)$ with the goal of providing seamless access for patients whose health care needs may change, requiring transfer from primary midwifery to obstetrician led care and vice versa over the course of pregnancy, 
Warmelink, J.C., Wiegers, T.A., Cock, T.P. de, Klomp, T., Hutton, E.K. Collaboration of midwives in primary care midwifery practices with other maternity care providers. Midwifery: 2017, 55(12), 45-52

childbirth and the postpartum period. The ultimate goal is to improve the quality of maternity care. To achieve this, a so-called 'integrated care' approach (CPZ, 2014) was suggested, including a proposal (Schippers, 2014) for a fusion of the maternity care professional societies or organisations (van der Lee, 2014). Health insurance companies supported this approach by strongly advising obstetricians and midwives to collaborate in a professional as well as a financial partnership (van der Lee, 2014). These changes could alter how maternity care has historically been organised, going from a strict echelon system to a more integrated maternity care system (de Vries et al., 2013; de Vries, 2014; Roman and van den Wijngaart, 2011). However, a thorough assessment of the collaboration is needed before making fundamental changes to the maternity care system. Understanding these working relations is critical given the organizational structure of maternity care in the Netherlands, the multidisciplinary focus, the involvement of diverse stakeholders and, ultimately, the quality and safety of care given to mothers and babies. Making such an assessment is important to get insight into the Dutch maternity care system; not only for the Netherlands, but also for other countries where midwifery-led care and home birth are increasingly being encouraged and where interdisciplinary professional collaboration may encounter similar issues and challenges. Dutch maternity care provides a unique research arena.

International research shows important associations of satisfaction with collaboration and: a) work-related and personal characteristics, such as gender, race, advanced education and profession (Bruner et al., 2011) and b) attitudes towards work, such as job satisfaction (Baggs and Ryan, 1990; Chang et al., 2009; Anthoine et al., 2014; Zhang et al., 2016) and turnover intentions (Anthoine et al., 2014) or retention (Baggs and Ryan, 1990; Zhang et al., 2016). Yet, prior quantitative studies on associations with 'satisfaction with collaboration' have often focused on the physician-nurse collaboration in hospitals. Little is known about primary care midwives' satisfaction with collaboration with other maternity care providers in the different echelons in the Netherlands and associations with characteristics of the midwives.

\section{Aim of the study}

In our study, we wanted to assess how satisfied primary care midwives are with collaboration with other maternity care providers and we wanted to assess the association between this 'satisfaction with collaboration' with factors such as a) their work-related and personal characteristics (age, non-Dutch origin, education and job type) b) attitudes towards work (job satisfaction and intention to leave) and c) collaboration characteristics (accessibility). The aim of this study was to provide insight into the professional working relations of primary care midwives in the Netherlands. Two research questions that were investigated in this study:

1. Are there differences in how primary care midwives experience satisfaction when collaborating with other maternity care providers?

2. What is the relationship between the primary care midwives' 'satisfaction with collaboration' and midwives' work-related and personal characteristics, attitudes towards their work and collaboration characteristics? 
Warmelink, J.C., Wiegers, T.A., Cock, T.P. de, Klomp, T., Hutton, E.K. Collaboration of midwives in primary care midwifery practices with other maternity care providers. Midwifery: 2017, 55(12), 45-52

\section{METHODS}

\section{Recruitment and enrolment of study participants}

This study is part of a larger project, the 'DELIVER-Study', of which background and design are described extensively in another publication (Manniën et al., 2012). Twenty of the 519 primary care midwifery practices in the Netherlands participated in the DELIVER study. Practices were sampled using three stratification criteria: practice type (dual or group practice), level of urbanization (urban or rural area) and region (north, centre, south). All 108 midwives from the twenty participating practices were asked to complete a written questionnaire in May 2010. Midwives who did not complete and return the questionnaire received a reminder. A comparison of background data of the participating midwives in the DELIVER practices with data from the midwifery occupational registration was presented in Wiegers et al. (2014).

\section{Measures}

Primary care midwives were asked to evaluate the interactions they had with three other maternity care providers in the first echelon (General Practitioners (GPs), Maternity Care Assistance Organisations (MCAOs) (in Dutch: kraamzorgaanbieders), Maternity Care Assistants (MCAs) (in Dutch: kraamverzorgenden)) and with three other maternity care providers in the secondary/tertiary echelon (obstetricians, clinical midwives, paediatricians). Collaboration was qualified in terms of satisfaction which respondents were asked to categorise as generally good, reasonable, moderate, poor or very variable (sometimes good, sometimes poor).

The questionnaire included work related characteristics, such as job-type (selfemployed practitioners, employees or locum), work experience (in years), practice type (group or dual practice), level of urbanization (urban or rural area or both), region (north, centre, south), country of midwifery education (in the Netherlands or abroad) and advanced postgraduate education (i.e. Masters degree (MSc)- yes/no). The questionnaire further included personal characteristics such as age (in years) ethnicity ('Were you and/or one of your parents born outside the Netherlands' (Dutch/non-Dutch) and gender (male/female). Regarding attitude towards work, perceived work pressure was measured based on the Perceived Work Pressure Scale (Ruijters and Stevens, 1992) and overall job satisfaction using the Job Satisfaction scale (Boumans et al., 1989). Both scales consist of general statements about the work situation, with answers on a 5-point Likert scale (strongly agree to strongly disagree). Another question 'To what extent are you satisfied with your work' is answered on a 4-point Likert scale. To measure the intention to leave (ITL), we asked the question 'Have you been thinking about seeking other employment in the past year' (yes/no). Regarding collaboration characteristics, the experiences with accessibility of GPs and MCAOs were assessed (name unknown / no time to retrieve phone number / I call the care provider, but not present / not called back / call back, but I'm absent) and if this was problematic (yes/no).

\section{Data analysis}

A new variable ('satisfaction with collaboration') was made using a 4-point rating scale; the outcome 'generally good' was recoded as ' 4 '; reasonable $=3$; 'moderate' $=$ 2 , 'poor' $=1$ and the outcome 'very variable' of the evaluation of the interactions was recoded as 'moderate' $=2$. A mean score for interaction with each of the other 
maternity care providers was calculated and an overall mean for all six maternity care providers. The satisfaction with the collaboration was then recoded into binary categories for interaction with each of the maternity care providers: 'well satisfied with collaboration' (generally good) (WSC-group) versus 'less satisfied with collaboration' (reasonable, moderate, poor, very variable and missing data) (LSCgroup). A Friedman test for correlated samples (a non-parametric repeated measures ANOVA) was carried out to assess differences in mean ranks between 'satisfaction with collaboration' with the six maternity care providers separately. Kendall's coefficient of concordance for ranks (W) was used to measure the agreement among the midwives. The strength of the agreement between the variables was considered as weak $W=.10$ to .29 ; moderate for $W=.30$ to .49 and strong for $W=.50$ to 1.0. Posthoc analyses (Wilcoxon signed-rank tests) were performed to determine the specific differences in ranking between each related group. A Bonferroni correction for the number of comparisons (k) was applied, so all effects are reported at a $0.0083(\alpha / \mathrm{k})$ level of significance (Field, 2009).

The variable 'job-type' was recoded into binary categories (self-employed practitioners versus employees or locum). Scores on scales were reversed if needed so that higher scores represented higher perceived work pressure and higher job satisfaction. The variable 'satisfied with your work' was dichotomised in satisfied (score 1 'very satisfied' and 2 'satisfied') and less satisfied (score 3 'varying satisfied' and 4 'not satisfied'). Bivariate analyses were carried out for comparing both groups ('well' versus 'less' satisfied with collaboration) for interaction with $\mathrm{GPs}, \mathrm{MCA}(\mathrm{O}) \mathrm{s}$, obstetricians, clinical midwives, paediatricians all together and separate - with respect to work related and personal characteristics, and attitudes towards work. Regarding collaboration characteristics, bivariate analyses were carried out to assess reported satisfaction with GPs, obstetricians and MCAOs. For comparing means with respect to the continuous, normally distributed variables, we used Student's t-test. If equal variances could not be assumed (Levene's test) or cases per group were $<30$ (de Vocht, 2014), non-parametric equivalents were used.

Spearman's rank-order correlation coefficient $(\rho)$ was used to assess the relationship between two continuous variables, at least one of which is not normally distributed. Pearson's chi-squared tests (or Fisher exact tests for small sample size) were used for comparing the distribution of percentages of both groups with respect to categorical predictors. Of the scales 'perceived work pressure' and 'overall job satisfaction' the mean scale scores for the whole group and two subgroups were calculated. A twotailed p-value of .05 or lower was considered statistically significant, except for the Wilcoxon tests. SPSS, version 22 was used for the analyses.

\section{Ethical approval and privacy issues}

This study was carried out as part of the national DELIVER study, which obtained ethical approval by the Medical Ethics Committee of our institute. Participation of the midwifery practices in this study was voluntary and consent to co-operate in this study was given. Privacy was guaranteed in accordance with Dutch legislation. Midwives' anonymity was maintained by using anonymous midwife and practice identifiers. 
Warmelink, J.C., Wiegers, T.A., Cock, T.P. de, Klomp, T., Hutton, E.K. Collaboration of midwives in primary care midwifery practices with other maternity care providers. Midwifery: 2017, 55(12), 45-52

\section{FINDINGS}

\section{Baseline characteristics of participants}

Overall, 99 (91.7\%) of the 108 primary care midwives, who were invited to participate, completed the questionnaire. The mean age of the participants was 37.5 years ( $\mathrm{SD}=10.9$; range 22-61 years). Most participants were female $(99.0 \%)$ and they, as well as their parents, were born in the Netherlands (87.9\%). The midwives were working in private practices, either as self-employed practitioners $(72.7 \%)$, or as employees or in locum positions $(27.3 \%)$. A few (4.0\%) worked together with one colleague in a duo-practice, $96.0 \%$ worked in group practices (practices with more than 2 midwives). $82.2 \%$ were educated in the Netherlands and $17.8 \%$ elsewhere (Belgium, the UK). The mean working years was 12.7 years $(\mathrm{SD}=9.9$; range $0-40$ years). Midwifery practices in the north region only worked in urban or rural areas, and in the south only in mixed areas.

\section{Satisfaction with collaboration}

Interactions with non-physicians are evaluated consistently higher than the interactions with physicians by primary care midwives (see Table A in appendix). Most primary care midwives described their interaction as 'generally good' with non-physicians: MCAs (79.8\%), clinical midwives (76.3\%) and MCAOs (68.4\%). Less than half of the midwives described the interaction with physicians as 'generally good': paediatricians (45.5\%), obstetricians (44.9\%), and GPs (38.4\%). A Friedman test was conducted to test for differences between 'satisfaction with collaboration' with the six groups of maternity care providers separately, namely with non-physicians: MCA (mean $=3.78$; mean rank $=4.21$ ), clinical midwives $($ mean $=3.75$; mean rank $=4.15)$, MCAO (mean $=3.66$; mean rank $=3.94)$ and with physicians: obstetricians (mean $=3.26$; mean rank $=3.02$ ), paediatricians (mean $=$ 3.11 ; mean rank $=2.90$ ) and GPs (mean 3.10; mean rank $=2.78)$. The test was significant: $\chi^{2}(5, N=89)=91.85 ; p<.0001$. Kendall's W was .21 .

Wilcoxon tests, with Bonferroni correction, showed significant differences between satisfaction with collaboration with physicians (GPs, obstetricians and paediatricians) and non-physicians (clinical midwives, MCAO, MCA) (all $p<0.0001$ ), except between MCAO and obstetricians $(p=0.001)$. There are no differences between satisfaction with collaboration within the group of physicians, or within the group of non-physicians. Interactions with non-physicians are ranked consistently higher than the interactions with physicians.

\section{Work-related and personal characteristics and their attitude towards work of the WSC-group}

Regarding the collaboration with GPs, significant differences show up between the group of midwives who are 'well satisfied with collaboration' (WSC-group- data in table B in appendix) versus the group of midwives who are 'less satisfied with collaboration' (LSC-group - data not in table). Midwives with higher mean working years $(\mathrm{WSC}=15.82$ years; $\mathrm{LSC}=10.74$ years; $p=0.012$ ), living in the south region \{north $(\mathrm{WSC}=26.9 \%)$, centre $(\mathrm{WSC}=35.2 \%)$, south $(\mathrm{WSC}=63.2 \%) ; p=0.037\}$, and with higher mean age (WSC $=41.16$ years; $\mathrm{LSC}=35.13$ years; $p=0.007$ ) are more likely to be well satisfied with GP collaboration.

Regarding the collaboration with $\mathrm{MCA}(\mathrm{O}) \mathrm{s}$ and clinical midwives there was a difference on level of urbanisation. Compared to the urban areas, in the rural or mixed areas the midwives were more satisfied: 
Warmelink, J.C., Wiegers, T.A., Cock, T.P. de, Klomp, T., Hutton, E.K. Collaboration of midwives in primary care midwifery practices with other maternity care providers. Midwifery: 2017, 55(12), 45-52

- For MCAOs: urban (WSC $=43.3 \%)$, rural (WSC $=80.0 \%)$, both $(\mathrm{WSC}=73.5 \%)$; $p=0.008$

- For MCAs: urban $(\mathrm{WSC}=60.0 \%)$, rural $(\mathrm{WSC}=95.0)$, both $(\mathrm{WSC}=85.7 \%) ; p=$ 0.004 ;

- For clinical midwives: urban $(\mathrm{WSC}=53.3 \%)$, rural $(\mathrm{WSC}=70.0 \%)$, both $(\mathrm{WSC}=$ $83.7 \%) ; p=0.014$.

Midwives from the southern region were more satisfied with collaboration with obstetricians \{ north $(\mathrm{WSC}=34.6 \%)$, centre $(\mathrm{WSC}=37.0 \%)$, south $(\mathrm{WSC}=78.9 \%)$; $p=0.003\}$. Midwives from non-Dutch origin were less satisfied with collaboration with paediatricians (WSC $=8.3 \% ; p=0.006$ ) than Dutch midwives. No relations were found between the overall mean satisfaction with collaboration and workrelated and personal characteristics and attitude towards work. A positive correlation was found between the variables age and working years $(r=0.924, p<0.001)$, between the level of urbanisation and region $\left(\chi^{2}(4, N=99)=46.865 ; p<0.001\right)$, and between the level of urbanisation and non-Dutch origin $\left(\chi^{2}(2, N=99)=6.468\right.$; $p=$ 0.039).

\section{Collaboration characteristics: accessibility}

Table 1 shows the experiences with or problems of accessibility in the interaction with GPs. In the interaction with GPs the midwives found it most problematic that 'they called the GP, but the GP was not present' $(60.6 \%)$, with significant differences between the WSC-group and LSC-group $(p=0.009)$. 'The GP did not call back' is problematic for $41.4 \%$ of the midwives $(p=0.002)$, and 'GP did call back, but the midwives themselves were absent' for $32.2 \%$ of the midwives $(p=0.015)$.

Table 2 shows the experiences with or problems of accessibility in the interaction with MCAOs. In the interaction with the MCAOs the midwives found it most problematic that 'there is no time to retrieve the phone number' $(25.3 \%)$ with no difference between the groups. 'They called the MCAO, but no one was present' was problematic for $23.5 \%$ of the midwives, with significant differences between the WSC-group and LSC-group in the interaction with MCAO $(p=0.022)$. 'The name of MCAO is unknown' was problematic for $23.2 \%$ of the midwives, with significant differences between the WSC-group and LSC-group in the interaction with MCAO $(p=0.000)$ and MCAs $(p=0.002)$.

\section{[TABLE 1] [TABLE 2]}

\section{DISCUSSION}

\section{Synopsis}

Satisfaction experienced by primary care midwives when collaborating with the different maternity care providers varies within and between primary and secondary/tertiary care. Interactions with non-physicians (clinical midwives, MCAO, MCA) are ranked consistently higher than the interactions with physicians (GPs, obstetricians and paediatricians). Midwives with more working years and who were older were more satisfied with the collaboration with the GPs. Midwives from the southern region of the Netherlands were more satisfied with collaboration with GPs and obstetricians. Compared to the urban areas, in the rural or mixed areas the midwives were more satisfied regarding the collaboration with $\mathrm{MCA}(\mathrm{O}) \mathrm{s}$ and 
Warmelink, J.C., Wiegers, T.A., Cock, T.P. de, Klomp, T., Hutton, E.K. Collaboration of midwives in primary care midwifery practices with other maternity care providers. Midwifery: 2017, 55(12), 45-52

clinical midwives. Midwives from non-Dutch origin were less satisfied with the collaboration with paediatricians compared to midwives from Dutch origin. We found associations of satisfaction with collaboration with problems in accessibility in some interactions. No relations were found between the overall mean satisfaction of collaboration and work-related and personal characteristics and attitude towards work.

Although the midwives in our study from the southern region were more satisfied regarding the collaboration with GPs, our study showed that overall the interactions of primary care midwives with GPs indicate that there is a lot of room for improvement. Collaboration problems may be historically rooted: the two maternity care providers in primary care have long struggled around the primaat- a regulation, introduced in 1941 and abolished in 2001, that advantaged midwives by requiring women to seek maternity care given by midwives instead of GPs if it was available in their neighbourhood (de Vries, 2005; Baarveld, 2007). The majority of midwives did not see a need for increased co-operation with GPs in maternity care (Baarveld, 2007). However, pregnant women considered their GP as an important care provider and contacted their GP an average of 3.6 times during pregnancy and post partum (Feijen-de Jong et al., 2013). Without good communication between care providers, this could lead to fragmented care arising from conflicting advice on pregnancy problems or complications, information loss, or even errors and the receipt of more interventions than are necessary (Feijen-de Jong, 2015). It is therefore essential to strengthen collaboration between GPs and midwives in care during pregnancy and post partum. Our findings indicate that the longer midwives have been working, or the higher the mean age, the better this relationship becomes. It could simply be about trust and familiarity with one another if they have been working alongside each other for a longer period of time, or by being more senior/confident when becoming older.

Our study showed that fewer than half of the participating midwives described the interaction with obstetricians and paediatricians in secondary/tertiary care as 'generally good'. Various studies have identified collaborative problems between obstetricians and primary care midwives in the Netherlands (e.g. Posthumus et al., 2013; Van der Lee, 2014). Primary care midwives experienced a power imbalance and a lack of trust and mutual acquaintanceship in their collaboration with obstetricians (Van der Lee, 2014). These perceptions can be explained from the historical perspectives of obstetricians' domination over midwives and the continuous disputes over midwives' authorities (van der Lee et al., 2014). The midwives from non-Dutch origin were less satisfied with the collaboration with paediatricians. It is possible that midwives of non-Dutch origin are less familiar with the autonomous, independent, medical profession of midwifery, and in their country of origin the obstetricians, and not the midwives, are working with paediatricians. The percentage of clinical midwives in the Netherlands has grown over the past decade from $22 \%$ to $29 \%$ of all registered midwives (Hassel et al., 2014). These clinical midwives work in hospitals under the supervision of an obstetrician. Most primary care midwives describe the interaction with clinical midwives as 'generally good', with no evidence for professional rivalry. Compared to the urban areas, in the rural or mixed areas the midwives were more satisfied regarding the collaboration with clinical midwives. Perhaps because in rural/mixed areas cooperation is more 
Warmelink, J.C., Wiegers, T.A., Cock, T.P. de, Klomp, T., Hutton, E.K. Collaboration of midwives in primary care midwifery practices with other maternity care providers. Midwifery: 2017, 55(12), 45-52

common, because care providers know each other and fewer professionals are involved in providing care.

Despite the finding that midwives in our study perceived problems in accessibility, most midwives described their interaction with $\mathrm{MCA}(\mathrm{O}) \mathrm{s}$ as generally good. Prior research showed that the duration of care of the maternity care assistant is closely related to the level of urbanisation: in large cities (most highly urbanised area), the average duration of maternity care assistance is 37 hours, which is nearly a third less than in rural (non-urbanised area) where the average duration of maternity care assistance is 52 hours (Wiegers and Janssen, 2006). We could argue there lies a possible relation in the average duration of maternity care assistance and the midwives' satisfaction with collaboration with $\mathrm{MCA}(\mathrm{O}) \mathrm{s}$ on the level of urbanisation in our study.

Our study did not find predicted associations of satisfaction with collaboration with attitudes towards work, such as job satisfaction, turnover intentions or retention (Baggs and Ryan, 1990; Chang et al., 2009; Anthoine et al., 2014; Zhang et al., 2016). Instead, we found differences on work-related and personal characteristics with some care providers, on the level of urbanisation, region, age, working years, non-Dutch origin and problems of accessibility in the interaction. We could not find profiles or characteristics of midwives who described the collaboration in general with all maternity care providers as 'generally good'.

\section{Strengths and limitations}

Our descriptive study gave a detailed cross-sectional insight into some aspects of the collaboration between primary care midwives and other maternity care providers in primary and secondary care in the Netherlands. Since collaboration between midwives and other maternity care providers is vital, it has been valuable to gain insight into this from the midwives' perspective. Our study provided an identification and understanding of some elements of interactions in maternity care and can be considered as part of a growing trend of identifying positive aspects of collaboration in maternity care (Van Helmond et al., 2015). Generalizability to primary care midwifery has been enhanced by the participation of DELIVER midwifery practices from various geographical locations in the country. The practices in our study were a good representation for the Netherlands in terms of region and degree of urbanisation and the background of midwives in the DELIVER practices resemble the primary care midwives in the Netherlands in 2010 (Warmelink, 2017; p. 83) The overall response rate of $91.7 \%$ can be considered as high.

The study has a number of limitations. Morgan et al. (2015) found as single most important and concrete element of successful inter-professional collaboration the 'constant opportunity for frequent, shared informal communication'. However, our study did not measure the opportunities for, or time spent in, informal consultations, occasionally or frequently. In addition to maternity care providers, pregnant women visit other health care providers in the community, such as complementary and alternative healthcare practitioners (Feijen-de Jong et al., 2015), mental health care professionals and self-help groups. Our study did not examine the collaboration with these other health care providers, nor did it examine the collaboration of midwives with other health system stakeholders, such as ambulance personnel, youth health care or health insurances companies (van Wensveen, 2014) and authorities on local, regional and national level (ten Hoope-Bender et al., 2016), or parents (Van Helmond et al., 2015). In addition, it may be too much of a simplification to qualify 
Warmelink, J.C., Wiegers, T.A., Cock, T.P. de, Klomp, T., Hutton, E.K. Collaboration of midwives in primary care midwifery practices with other maternity care providers. Midwifery: 2017, 55(12), 45-52

collaboration in terms of the satisfaction of the interaction the midwives have with other maternity care providers. Furthermore, our study collected data on collaboration characteristics for some care providers, but not for all six groups of maternity care providers. Our study only presents data from primary care midwives and we would recommend future research to explore the views and experiences/satisfaction from all of the key maternity providers, to identify barriers and facilitators to collaboration.

This cross-sectional study is observational and descriptive in nature and cannot be used to determine causal relationships. Differentiation between the 20 DELIVER practices is difficult, given the relatively small sample size. Only bivariate associations were examined, with no control for effect of predictors on satisfaction with collaboration. For more robust results, including prediction -, association - or class analyses (Vermunt, 2004; de Vocht, 2014; Wurpts and Geiser, 2014), a larger study with all relevant variables and addressing potential sources of bias is required. Nevertheless, our study can be seen as a pilot study and can indicate possible associations. Therefore it can be useful in generating hypotheses for future research.

\section{Implications}

Regarding midwifery education, Dutch midwifery training has been considered to be among the best in the world (de Vries et al., 2009). Anticipating the new professional profile of the Royal Dutch Organization of Midwives (KNOV, 2014), the Midwifery Academy Amsterdam-Groningen (AVAG) implemented a change in the curriculum, increasing the emphasis on teaching evidence-based practice, increasing the opportunities for inter-professional training, including providing care in case of moderate risk indications. On the issue of inter-professional education the opinions are divided. According to King et al. (2012), inter-professional education is the natural precursor to inter-professional practice. Inter-professional education can improve knowledge of each other's professional skills and boundaries, leading to better understanding of each other's role and better cooperation. However, educational interventions are not the only key to improving the collaboration between midwives and obstetricians. Van der Lee (2014) indicated that collaboration might already significantly improve by practical interventions aimed at improving the co-ordination of maternity care, the means of communication, the clarity about professional boundaries and the sharing of information and activities.

According to van der Lee (2014) organisational problems are probably best assessed and solved by a joint effort of the maternity care providers and their professional societies. Primary care midwives and other maternity care providers provide care and should inform and/or involve each other about care plans/decisions, especially in case of the transfer from primary midwifery to obstetrician led care and vice. The involvement of GPs and the accessibility back and forth in collaborative care and the sharing of relevant information during pregnancy and post partum appears to be in need of improvement. One might think of new communication tools (Morgan et al., 2015), like an integrated digital environment facilitating the communication, (Feijende Jong, 2015), or common clinical records that can be shared quickly and easily when and where convenient (Morgan et al., 2015). Exchanging contact information, such as name and phone number of care providers, with MCAOs or other maternity care providers can be a simple but effective measure in enlarging the accessibility. To address relational problems between disciplines, one might also think of creating multiple opportunities for frequent, informal communication in a shared physical or 
digital work space (Morgan et al., 2015) or in inter-professional education (King et al., 2012; van der Lee, 2014), where mutual respect and 'professional courtesy' is required (Reiger and Lane, 2009). Similar to the role Xyrichis and Lowton (2008) saw for nurses in primary care, one might see a role for midwives in interprofessional teamwork, as the largest professional group dealing with direct client care. Midwives could place themselves in a position where their professional input is acknowledged both for client benefits and for the effective functioning of the interprofessional team.

In addition to this descriptive study, future exploratory or explanatory/hypotheticaldeductive research can give more insight in the collaborative practice in everyday work setting, including transition points from primary to secondary care, and vice versa. Direct observation has the potential to identify elements of inter-professional collaboration that are not so obvious to individuals when asked to self-report, and qualitative research can gain better understanding of the complex phenomena of inter-professional collaboration, inter-professional collaborative practice and/or teamwork in primary maternity care. In order to do more explanatory or deductive analysis, a larger quantitative study can further explore the meaning of communication and collaboration, the contextual components on the effectiveness of interdisciplinary collaboration, such as clear and respected boundaries, mutual trust, acknowledgement of interdependence, acceptance of shared responsibilities (Downe et al., 2010), and the influencing factors, such as the history of collaboration (Corbally et al., 2007; van der Lee, 2014), supportive organizational structure, availability of resources and positive individual attitude (Downe et al., 2010). The conceptual framework of Boon et al. 2014 can be used to document the evolution of team-oriented maternity care initiatives over time. Next steps in the research need to include other members of the multidisciplinary team if we really want to understand barriers/facilitators to collaboration. Avery et al. (2012) described five main themes for successful and sustainable models of midwife and obstetrician collaborative practice: impetus for collaboration, foundations of collaborative care, commitment to partnership, care integration, and inter-professional education. King et al. (2012) conclude that the success of interdisciplinary teams is dependent on professional competence, inter-professional respect, and a common orientation to the patient. Valentijn et al. (2015) distinguished five different themes in order to evaluate the collaboration processes of a partnership: shared ambition, mutual gains, process management, relationship and organisation dynamics. All these factors can be important to include in future studies to develop deeper understanding of satisfaction with collaboration.

\section{CONCLUSION}

Our descriptive study indicates that satisfaction with collaboration of primary care midwives with the different maternity care providers varies within and between the echelons of care. Interactions with non-physicians (clinical midwives, MCAO, MCA) are ranked consistently higher/more positive than the interactions with physicians (GPs, obstetricians and paediatricians), independent of the echelon in which they worked. We found associations of satisfaction with collaboration with the level of urbanisation, region, age, working years, non-Dutch origin, and problems in accessibility in some interactions. Future exploratory or explanatory research will provide more insight in the collaborative practice in everyday work setting. 
Warmelink, J.C., Wiegers, T.A., Cock, T.P. de, Klomp, T., Hutton, E.K. Collaboration of midwives in primary care midwifery practices with other maternity care providers. Midwifery: 2017, 55(12), 45-52

\section{COMPETING INTERESTS}

The authors declare that they have no competing interests.

\section{ETHICAL STATEMENT}

\section{Ethical approval}

This study was carried out as part of the national DELIVER study, which obtained ethical approval by the Medical Ethics Committee of our institute the VU University Medical Centre in Amsterdam, the Netherlands (WC 008-100).

\section{Funding sources}

This study was funded by the Academy of Midwifery Amsterdam-Groningen.

\section{Clinical Trial Registry and Registration number}

Not applicable.

\section{Authors' contribution}

TW, TK and EH originated and supervised the DELIVER study and the recruitment the midwifery practices. CW analysed the data and drafted the manuscript. All authors read and corrected draft versions of the manuscript and approved the final manuscript.

\section{ACKNOWLEDGMENTS}

This study was funded by the Academy of Midwifery Amsterdam-Groningen. The authors are indebted to the midwives who participated in this study and the DELIVER research assistances, Ruth Baron, Monique Pereboom and Myrte Westerneng.

\section{APPENDIX A. SUPPLEMENTARY MATERIAL}

\section{REFERENCES}

Anthoine, E., Delmas, C., Coutherut, J., Moret, L., 2014. Development and psychometric testing of a scale assessing the sharing of medical information and interprofessional communication: the CSI scale. BMC Health Services Researchs 14, 1-9. http:// dx.doi.org/10.1186/1472-6963-14-126.

Avery, M.D., Montgomery, O., Brandl-Salutz, E., 2012. Essential components of successful collaborative maternity care models: the ACOG-ACNM project. Obstetrics and Gynecology Clinics of North America 39, 423-434. http://dx.doi.org/10.1016/j.ogc.2012.05.010.

Baarveld, F., 2007. Gedeelde zorg voor zwangeren. Verloskundigen zien weinig in meer samenwerking met huisartsen [Shared care for pregnant women. Midwives don't have sympathy for more cooperation with general practitioners]. Medisch Contact 62, 14921494.

Baggs, J.G., Ryan, S.A., 1990. ICU nurse-physician collaboration \& nursing satisfaction. Nursing Economics 8, 386-392.

Boon, H., Verhoef, M., O'Hara, D., Findlay, B., 2004. From parallel practice to integrative health care: a conceptual framework. BMC Health Services Research 4, 15.

Boumans, N.P.G., Landeweer, J.A., Houtem, J.H.M., 1989. Arbeidsvoldoening bij verpleegkundigen. Factor- en betrouwbaarheidsanalyse van een meetinstrument. [Job satisfaction among nurses. Factor analysis and reliability analysis of a measuring instrument]. Tijdschrift voor sociale gezondheidszorg 67, 199-203.

Bruner, P., Waite, R., Davey, M.P., 2011. Providers' perspectives on collaboration. Journal of Integrated Care 11, 1-9. 
Warmelink, J.C., Wiegers, T.A., Cock, T.P. de, Klomp, T., Hutton, E.K. Collaboration of midwives in primary care midwifery practices with other maternity care providers. Midwifery: 2017, 55(12), 45-52

Chang, W.Y., Ma, J.C., Chiu, H.T., Lin, K.C., Lee, P.H., 2009. Job satisfaction and perceptions of quality of patient care, collaboration and teamwork in acute care hospitals. Journal of Advanced Nursing 65, 1946-1955. http://dx.doi.org/10.1111/ j.13652648.2009.05085.x.

Coffie, D., Wiegers, T., Schellevis, F., 2003. Het gebruik van verloskundige zorg en kraamzorg [The use of midwifery care and postpartum care]. Tijdschrift voor verloskundigen 28, 315-320.

College voor zorgverzekeringen, 2003. Verloskundig Vademecum [Obstetric Manual]. Diemen: College voor zorgverzekeringen.

Corbally, M.A., Scott, P.A., Matthews, A., Gabhann, L.M., Murphy, C., 2007. Irish nurses' and midwives' understanding and experiences of empowerment. Journal of Nursing Management 15, 169-179.

CPZ (College Perinatale Zorg), 2014. Samenwerking in de geboortezorg: positieve ontwikkelingen, knelpunten en oplossingen [Cooperation in maternity care: positive developments, problems and solutions] 18 maart. URL 〈https://www.rijksoverheid. nl/documenten/brieven/2014/03/18/brief-over-samenwerking-indegeboortezorg $\rangle$.(Accessed 10 September 2015).

de Geus M., Cadée F., 2015. Midwifery in the Netherlands. 〈http://www.knov.nl/samenwerken/tekstpagina/489/midwifery-in-the-netherlands/〉 (Accessed 7 December 2015).

de Jonge, A., de Vries, R., Lagro-Janssen, A.L., Malata, A., Declercq, E., Downe, S., Hutton, E.K., 2015. The importance of evaluating primary midwifery care for improving the health of women and infants. Frontiers of Medicine 2, 1-6. http://dx.doi.org/10.3389/fmed.2015.00017.

de Vries, R., 2005. A Pleasing Birth: Midwives and Maternity Care in the Netherlands. Amsterdam University Press, Amsterdam.

de Vries, R., Wiegers, T.A., Smulders, B., Teijlingen, E. van, 2009. The Dutch obstetrical system; vanguard of the future in maternity care. In: Davis-Floyd, R.E., Barclay, L., Daviss, B.-A., Tritten, J. (Eds.), Birth Models That Work. University of California Press, Berkely, Los Angeles, London, 31-53.

de Vries, R., Nieuwenhuijze, M., Buitendijk, S.E., 2013. members of Midwifery Science Work Group. What does it take to have a strong and independent profession of midwifery? Lessons from the Netherlands. Midwifery 29, 1122-1128.

de Vries, R., 2014. Verloskunde staat voor een historisch keerpunt. [Midwifery care at historical turning point] Volkskrant 27 maart.

de Vocht, A., 2014. Basishandboek SPSS 22 [Basic manual SPSS 22]. Bijleveld Press. Downe, S., Finlayson, K., Fleming, A., 2010. Creating a collaborative culture in maternity care. Journal of Midwifery \& Women's Health 55, 250-254. http://dx.doi.org/10.1016/j.jmwh.2010.01.004.

Feijen-de Jong, E.I., Baarveld, F., Jansen, D.E., Ursum, J., Reijneveld, S.A., Schellevis, F.G., 2013. Do pregnant women interaction their general practitioner? A registerbased comparison of healthcare utilisation of pregnant and non-pregnant women in general practice. BMC Family Practice 14, 1-7. http://dx.doi.org/10.1186/1471-2296-14-10

Feijen-de Jong, E.I., Jansen, D.E., Baarveld, F., Spelten, E., Schellevis, F., Reijneveld, S.A., 2015. Determinants of use of care provided by complementary and alternative health care practitioners to pregnant women in primary midwifery care: a prospective cohort study. BMC Pregnancy and Childbirth 15, 1-11. http://dx.doi.org/10.1186/s12884-015-0555-7.

Feijen-de Jong, E.I., 2015. On the Use and Determinants of Prenatal Healthcare Services. Chapter 7: General Discussion (thesis). RuG, Groningen.

Field, A., 2009. Discovering Statistics Using SPSS third edn.. Sage Publications Ltd, 372373.

Frank, J.R., Danoff, D., 2007. The CanMEDS initiative: implementing an outcomesbased framework of physician competencies. Medical Teacher 29, 642-647. http://dx.doi.org/10.1080/01421590701746983.

Hassel, D.T.P. van, Kasteleijn, A., Kenens, R., 2014. Cijfers uit de registratie van verloskundigen: peiling 2013 [Data from the registration of midwives 2013]. NIVEL, Utrecht.

Houben-Van Herten M., 2013. Autochtone moeders maken vaker gebruik van kraamzorg dan allochtone moeders, Bevolkingstrends, 8 januari $\langle$ http://www.cbs.nl/nl- 
Warmelink, J.C., Wiegers, T.A., Cock, T.P. de, Klomp, T., Hutton, E.K. Collaboration of midwives in primary care midwifery practices with other maternity care providers. Midwifery: 2017, 55(12), 45-52

$\mathrm{NL} /$ menu/themas/bevolking/publicaties/bevolkingstrends/archief/2013/2013-

bevolkingstrendsgebruik-kraamzorg-art.htm) (Accessed 18 November 2016).

Joint Commission on Accreditation of Healthcare Organizations, 2004. Preventing infant death and injury during delivery. Joint Commission Perspectives 24, 14-15.

Kerssens, J., 1991. Het oordeel kraamvrouwen over thuiskraamzorg [The evaluation of postpartum women about postpartum care at home]. 2004. NIVEL, Utrecht.

King, T.L., Laros, R.K., Jr, Parer, J.T., 2012. Interprofessional collaborative practice in obstetrics and midwifery. Obstetrics and Gynecology Clinics of North America 39 (3), $411-$ 422. http://dx.doi.org/10.1016/j.ogc.2012.05.009.

KNOV, 2014. Beroepsprofiel. [Profile of the profession] Juni. 〈http://www.knov.nl/scholing-enregistratie/tekstpagina/31/beroepsprofiel/> 10 September 2015.

Manniën, J., Klom, T., Wiegers, T., et al., 2012. Evaluation of primary care midwifery in the Netherlands: design and rationale of a dynamic cohort study (DELIVER). BMC Health Services Research 12, 1-23. http://dx.doi.org/10.1186/1472-6963-12-69.

Morgan, S., Pullon, S., McKinlay, E., 2015. Observation of interprofessional collaborative practice in primary care teams: an integrative literature review. pii: S0020-7489(15)

00070-XInternational Journal of Nursing Studies 52 (17), 1217-1230.

http://dx.doi.org/10.1016/j.jnurstu.2015.03.008.

Posthumus, A.G., Schölmerich, V.L., Waelput, A.J., et al., 2013. Bridging between professionals in perinatal care: towards shared care in the Netherlands. Maternal and Child Health Journal 17, 1981-1989. http://dx.doi.org/10.1007/s10995-012-1207-4.

Reiger, K.M., Lane, K.L., 2009. Working together: collaboration between midwives and doctors in public hospitals. Australian Health Review 33, 315-324.

Rowland T., McLeod D., Froese-Burns N., 2012. Comparative study of maternity systems URL: 〈http://www.health.govt.nz/publication/comparative-study-maternitysystem). (Accessed 13 June 2016).

Ruijters, R.F.M., Stevens, F.J.C., 1992. Organisatiestructuur, rolduidelijkheid, arbeidssatisfactie en het oordeel van verpleegkundigen over de samenwerking met artsen. [Organizational structure, role clarity, job satisfaction and the opinion of nurses about the collaboration with doctors]. Verpleegkunde 2, 106-114.

Schippers E., 2014. Kamerbrief over voortgang zwangerschap en geboorte [Letter about progress on pregnancy and birth]. 2 Jun.

〈https://www.rijksoverheid.nl/documenten/kamerstukken/2014/06/02/kamerbrief-overvoortgangzwangerschap-en-geboorte). (Accessed 10 September 2015).

Schölmerich, V.L., Posthumus, A.G., Ghorashi, H., Waelput, A.J., Groenewegen, P., Denktaş, S., 2014. Improving interprofessional coordination in Dutch midwifery and obstetrics: a qualitative study. BMC Pregnancy and Childbirth 14, 1-8.

http://dx.doi.org/10.1186/1471-2393-14-145.

Simpson, K.R., Knox, G.E., 2003. Adverse perinatal outcomes. Recognizing, understanding \& preventing common accidents. Association of Women's Health, Obstetric and Neonatal Nurses 7, 224-235.

ten Hoope-Bender, P.T., Lopes, S.T., Nove, A., Michel-Schuldt, M., Moyo, N.T., Bokosi, M., Codjia, L., Sharma, S., Homer, C., 2016. Midwifery2030, a woman's Pathway to health: what does it mean? Midwifery 32, 1-6.

The Netherlands Perinatal Registry, 2014. Perinatal Care in the Netherlands 2013. The Netherlands Perinatal Registry, Utrecht.

Valentijn, P.P., Vrijhoef, H.J., Ruwaard, D., de Bont, A., Arends, R.Y., Bruijnzeels, M.A., 2015. Exploring the success of an integrated primary care partnership: a longitudinal study of collaboration processes. BMC Health Services Research 15, 1-8. http://dx.doi.org/10.1186/s12913-014-0634-x.

van der Lee, N., 2014. Tailoring CanMEDS for training in Obstetrics and Gyneacology in the Netherlands (thesis). VU Amsterdam, 93-105.

van der Lee, N., Driessen, E.W., Houwaart, E.S., Caccia, N.C., Scheele, F., 2014. An examination of the historical context of interprofessional collaboration in Dutch obstetrical care. Journal of Interprofessional Care 28, 123-127. http://dx.doi.org/10.3109/13561820.2013.869196.

van der Lee, N., Driessen, E.W., Scheele, F., 2016. How the past influences interprofessional collaboration between obstetricians and midwives in the Netherlands: 
Warmelink, J.C., Wiegers, T.A., Cock, T.P. de, Klomp, T., Hutton, E.K. Collaboration of midwives in primary care midwifery practices with other maternity care providers. Midwifery: 2017, 55(12), 45-52

findings from a secondary analysis. Journal of Interprofessional Care 30 (1), 71-76. http://dx.doi.org/10.3109/13561820.2015.1064876.

Van Helmond, I., Korstjens, I., Mesman, J., et al., 2015. What makes for good collaboration and communication in maternity care? A scoping study. International Journal of Childbirth $5,210-223$.

van Teijlingen, E.R., 1990. The profession of maternity home care assistant and its significance for the Dutch midwifery profession. International Journal of Nursing Studies 27, 355-366.

van Wensveen, D., 2014. TNS NIPO. Zorgconsumenten én zorgprofessionals gefrustreerd over invloed zorgverzekeraars [Consumers of care ánd healthcare professionals frustrated about the impact of Health Insurance companies] URL:

〈http://www.tnsnipo.com/nieuws/persberichten/zorgconsumenten-enzorgprofessionalsgefrustreerd// (Accessed 8 January 2016).

Vermunt, J.K., 2004. Toepassingen van Latente Klasse Analyse in Sociaal Wetenschappelijk Onderzoek [Applications of Latent Class Analysis in Social Research]. Sociale Wetenschappen 47, 2-14.

Warmelink, J.C., Hoijtink, K., Noppers, M., Wiegers, T.A., de Cock, T.P., Klomp, G.M.R., Hutton, E.K., 2015. An explorative study of factors contributing to the job satisfaction of primary care midwives. Midwifery $31,482-488$. http://dx.doi.org/10.1016/j.midw.2014.12.003.

Warmelink J., 2017. The organisation of midwifery care in the Netherlands; thesis. Amsterdam: VU Amsterdam, The Netherlands.

Wiegers, T.A., Janssen, B.M., 2006. Monitor Verloskundige zorgverlening, eindrapportage [Monitor midwifery care survey, final report]. NIVEL, Utrecht.

Wiegers, T.A., 2006. Adjusting to motherhood maternity care assistance during the postpartum period: how to help new mothers cope. Journal of Neonatal Nursing 12, 163 171. http://dx.doi.org/10.1016/j.jnn.2006.07.003.

Wiegers, T.A., Warmelink, J.C., Spelten, E.R., Klomp, G.M.T., Hutton, E.K., 2014. Workload of primary care midwives in 2010. Midwifery 30, 991-997. http://dx.doi.org/10.1016/j.midw.2013.08.010.

World Health Organisation, 2016. Declaration from the International Conference on Primary Health Care, Alma-Ata, September 1978. URL 〈http://www.euro.who.int/en/publications/policy-documents/declaration-of-alma-ata,-1978〉. (Accessed 7 September).

Wurpts, I.C., Geiser, C., 2014. Is adding more indicators to a latent class analysis beneficial or detrimental? Results of a Monte-Carlo study. Frontiers in Psychology 5, 1-15. http://dx.doi.org/10.3389/fpsyg.2014.00920.

Xyrichis, A., Lowton, K., 2008. What fosters or prevents interprofessional teamworking in primary and community care? A literature review. International Journal of Nursing Studies 45, 140-153.

Zhang, L., Huang, L., Liu, M., Yan, H., Li, X., 2016. Nurse-physician collaboration impacts job satisfaction and turnover among nurses: a hospital-based cross-sectional study in Beijing. International Journal of Nursing Practicet 22 (3), 284-290. http:// dx.doi.org/10.1111/ijn.12424.

Zorginstituut Nederland, 2015. Kraamzorg, verzekerd van een goed begin? [Maternity care assistance: ensured of a good start?]. 
Warmelink, J.C., Wiegers, T.A., Cock, T.P. de, Klomp, T., Hutton, E.K. Collaboration of midwives in primary care midwifery practices with other maternity care providers. Midwifery: 2017, 55(12), 45-52

\section{BOX, TABLES AND FIGURE}

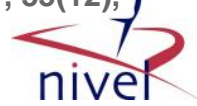

\section{Box 1 \\ Collaboration in maternity care in the Netherlands.}

In the Netherlands, autonomous working primary care midwives provide care to women with a 'normal' physiological or low-risk pregnancy and birth, and obstetricians and clinical midwives, working under the responsibility of the obstetrician, provide care to women with high risk or complicated pregnancy and birth. This style of practice can be called a collaborative model of team-oriented health care practice: practitioners, who normally practice independently from each other, share information concerning a particular patient who has been (is being) treated by each of them (Boon et al., 2004). The independent primary care midwife plays a key role as provider of standard maternity care in the Netherlands and provides one-to-one care to women during pregnancy, birth and the postpartum period in solo or group practices of midwives. In 2013, 85.4\% of all pregnant women in the Netherlands started antenatal care with a primary care midwife, $50.6 \%$ started labour with a primary care midwife and $28.6 \%$ of all births $(n=167.159)$ were supervised by a primary care midwife at home or in a hospital or birth centre (The Netherlands Perinatal Registry, 2014).

Postpartum care is usually provided by primary care midwives and maternity care assistants (MCAs) (in Dutch: kraamverzorgenden) unless the woman and/or baby is hospitalised (Wiegers, 2006; de Vries et al., 2009). Although there is a lack of evidence about the care of MCAs (Zorginstituut Nederland, 2015), MCAs form an essential part of the Dutch maternity care system (Kerssens, 1991; Wiegers, 2006; Wiegers and Janssen, 2006; de Vries et al., 2009). Primary care midwives depend on the assistance they receive from maternity care assistants. During a home birth or during midwife-led hospital (policlinical) birth, the maternity care assistant assists the midwife and helps and advises the new mother with the baby during the postnatal period at home. The existence of this profession, an occupation unique to the Netherlands (de Vries, 2005), allows midwives to concentrate on midwifery tasks, and reduces the costs of care by freeing up midwives and physicians (van Teijlingen, 1990). It also enables pregnant women to consider giving birth at home or in a policlinical setting. Almost all of the women (95\%) who give birth at home or in a policlinical setting use the services of MCAs (Coffie et al., 2003). However, nonDutch women (such as women from Turkish and Moroccan backgrounds) were not so familiar with the Dutch system of maternity care and make less use of this service (Houben-Van Herten, 2013).

Primary care midwives in the Netherlands engage in different types of work-related collaborations (KNOV, 2014): collaboration with clients and their families, with coworkers in midwifery practices and other maternity care providers in primary care, such as general practitioners (GPs), maternity care assistance organisations (MCAOs) (in Dutch: kraamzorgaanbieders) and MCAs, and in secondary care, such as obstetricians, clinical midwives and paediatricians in departments of obstetrics and neonatology at the local hospital. Cooperation between primary and secondary care 
Warmelink, J.C., Wiegers, T.A., Cock, T.P. de, Klomp, T., Hutton, E.K. Collaboration of midwives in primary care midwifery practices with other maternity care providers. Midwifery: 2017, 55(12), 45-52

is organised in Maternity Care Consultation and Collaboration Groups (in Dutch: VSVs = Verloskundige samenwerkingsverbanden) around each hospital. There are several multidisciplinary guidelines, protocols, care pathways and an Obstetric Indication List (in Dutch: VIL: verloskundige indicatielijst) (College voor zorgverzekeringen, 2003) for maternity care, which include recommendations about care and care provider. Furthermore, primary care midwives collaborate with other health system stakeholders, such as health insurances companies and (public health) authorities on local, regional and national level. As case manager of the client, midwives might co-ordinate and organise the collaboration between different disciplines with the aim to provide continuity of care to the client. Dutch primary care midwives spend an increasing amount of time on non-client-related activities, such as meetings and practice organisation (Wiegers et al., 2014).

The Dutch maternity care model has been held out as example of how to slow or reverse the march towards medicalisation of birth and technology driven specialist midwifery and maternity care. However, unexpected high perinatal mortality raised concerns about the quality of the Dutch maternity care system resulting in a call for system change to improve care. While the contemporary echelon system recognises roles for primary, secondary and tertiary care providers, consensus seems to be building for a more integrated maternity care system.

Table 1. The experiences or problems in accessibility in the interaction between individual primary care midwives with general practitioners (GPs) (n (\%)).

\begin{tabular}{|c|c|c|c|c|c|c|}
\hline & \multirow{2}{*}{\begin{tabular}{|l} 
Stated as \\
problematic N \\
$(\%)$
\end{tabular}} & \multicolumn{5}{|c|}{ Extent of problem in accessibility } \\
\hline & & Always & Often & $\begin{array}{r}\text { Some- } \\
\text { times }\end{array}$ & Never & Missing \\
\hline \multirow{2}{*}{$\begin{array}{l}\text { Name of care provider is } \\
\text { unknown }\end{array}$} & 18 & 1 & & 30 & 68 & \\
\hline & $(18.2 \%)$ & $(1.0 \%)$ & & $(30.3 \%)$ & $(68.7 \%)$ & \\
\hline \multirow{2}{*}{$\begin{array}{l}\text { No time to retrieve phone } \\
\text { number }\end{array}$} & 8 & & 3 & 15 & 80 & 1 \\
\hline & $(8.1 \%)$ & & $(3.0 \%)$ & $(15.2 \%)$ & $(80.8 \%)$ & $(1.0 \%)$ \\
\hline \multirow{2}{*}{$\begin{array}{l}\text { I call the care provider, } \\
\text { but he/she is not presen }\end{array}$} & 60 & 2 & 41 & 52 & 2 & 2 \\
\hline & $t(60.6 \%)^{x}$ & $(2.0 \%)$ & (41.4\%) & $(52.5 \%)$ & $(2.0 \%)$ & $(2.0 \%)$ \\
\hline \multirow{2}{*}{$\begin{array}{l}\text { Care provider does not } \\
\text { call back }\end{array}$} & 41 & 1 & 9 & 48 & 40 & 1 \\
\hline & $(41.4 \%)^{*}$ & $(1.0 \%)$ & $(9.1 \%)$ & $(48.5 \%)$ & $(40.4)$ & $(1.0 \%)$ \\
\hline \multirow{2}{*}{$\begin{array}{l}\text { Care provider does call } \\
\text { back, but l'm absent }\end{array}$} & 32 & 3 & 62 & 33 & & 1 \\
\hline & $(32.2 \%)^{\pi}$ & $(3.0 \%)$ & $(62.6 \%)$ & $(33.3 \%)$ & & $(1.0 \%)$ \\
\hline
\end{tabular}

* Significant differences between the group primary care midwives who were well (WSCgroup) versus less (LSC-group) satisfied with the collaboration in the interaction with GPs. 
Warmelink, J.C., Wiegers, T.A., Cock, T.P. de, Klomp, T., Hutton, E.K. Collaboration of midwives in primary care midwifery practices with other maternity care providers. Midwifery: 2017, 55(12), 45-52

Table 2. The experiences or problems in accessibility in the interaction between individual primary care midwives with maternity care assistance organisations (MCAOs)(n (\%)).

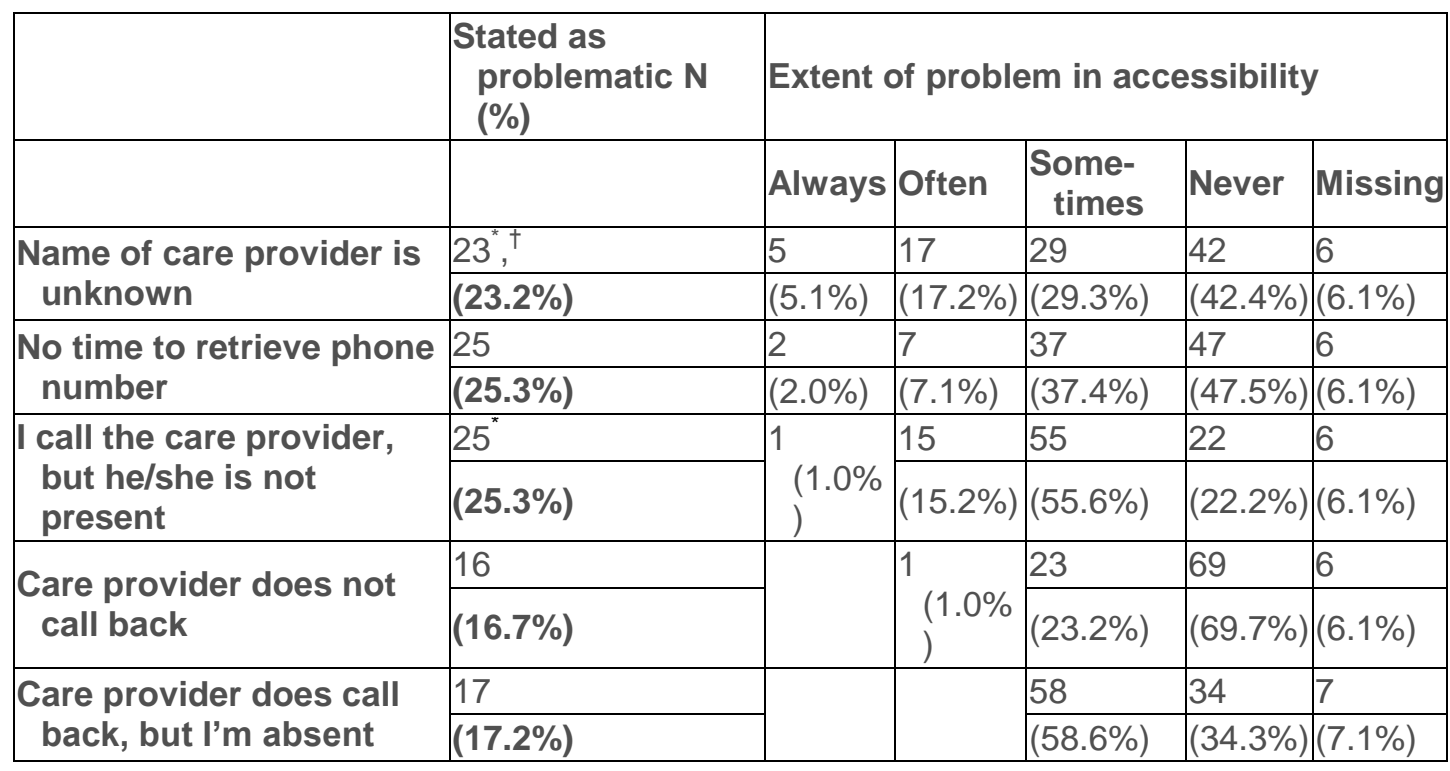

*Significant differences between the group primary care midwives who were well (WSCgroup) versus less (LSC-group) satisfied with the collaboration in the interaction with maternity care assistance organisations (MCAOs).

†Significant differences between the group primary care midwives who were well (WSCgroup) versus less (LSC-group) satisfied with the collaboration in the interaction with maternity care assistants (MCAs). 